\title{
The simple arithmetic of carbon pricing and stranded assets
}

\author{
Frederick van der Ploeg • Armon Rezai
}

Received: 28 July 2017 / Accepted: 5 October 2017 / Published online: 20 December 2017

(C) The Author(s) 2017. This article is an open access publication

\begin{abstract}
A simple rule for the optimal global price of carbon is presented, which captures the geophysical, economic, and ethical drivers of climate policy as well as the effect of uncertainty about future growth of consumption. There is also a discussion of the optimal carbon budget and the amount of unburnable carbon and stranded fossil fuel reserves and a back-on-theenvelope expression are given for calculating these. It is also shown how one can derive the end of the carbon era and peak warming. This simple arithmetic for determining climate policy is meant to complement the simulations of large-scale integrated assessment model, and to give analytical understanding of the key determinants of climate policy. The simple rules perform very well in a full integrated assessment model. It is also shown how to
\end{abstract}

This article is part of the Topical Collection: Energy and Climate Economic Modelling

Guest Editors: Milan Šcasný and Anna Alberini

F. van der Ploeg $(\bowtie)$

Department of Economics, University of Oxford, Manor Road

Building, Oxford OX1 3UQ, UK

e-mail: rick.vanderploeg@economics.ox.ac.uk

F. van der Ploeg

VU University Amsterdam, Amsterdam, Netherlands

F. van der Ploeg

St. Petersburg State University, 7/9 Universitetskaya nab, St.

Petersburg, Russia 199034

A. Rezai

Department of Socioeconomics, Vienna University of Economics and Business, Welthandelsplatz 1, 1020 Vienna, Austria

e-mail: armon.rezai@wu.ac.at

A. Rezai

IIASA, Schlossplatz 1, 2361 Laxenburg, Austria take account of a $2{ }^{\circ} \mathrm{C}$ upper limit on global warming. Steady increases in energy efficiency do not affect the optimal price of carbon, but postpone the carbon-free era somewhat and if technical progress in renewables and economic growth are strong leads to substantially lower cumulative emissions and lower peak global warming.

Keywords Social cost of carbon - Carbon budget · Peak warming $\cdot$ End of carbon era

JEL codes $\mathrm{H} 21 \cdot \mathrm{Q} 51 \cdot \mathrm{Q} 54$

\section{Introduction}

Climate change is the world largest externality (Stern 2007) and climate policy needs to correct this externality by establishing cost transparency in the energy market. Fossil fuels are currently too cheap, since users of this energy type are not shouldering the cost of future climate damages and renewable energy is still in its infancy. The introduction of a carbon tax (or a cap on overall emissions levels) will shift demand in the global energy system away from dirty towards carbon-free energy sources. It will also increase the cost of energy overall, at least in the short run while efficiency improvements in the renewable energy sector are still ongoing, making investments in energy demand reductions more attractive. Here we present the arithmetic underlying carbon pricing and show how to calculate in a simple way the optimal timing of the transition to the carbon-free era and the amount of cumulative carbon emissions and peak global warming. Our rule for the carbon price is simple but robust and can be useful for analysing the 
effects of carbon pricing on patterns of energy generation and energy use.

Climate policy has to combine ethical judgments with projections about future economic, technological, and climatic developments. Integrated assessment models (IAMs) aim to do this, but have been criticised for being highly complex, insufficiently open access, and underestimating the threats of climate change (Stern 2016). We present a simple framework that captures the essence of IAMs, makes their underlying assumptions transparent, and opens the discussion of the political and social obstacles to climate policy. Our costbenefit analysis of climate action yields a simple rule for the optimal global price of carbon in the presence of a backstop renewable energy source that is currently more expensive than fossil fuel. This price is proportional to current world GDP and depends on key ethical considerations, damage flows and geophysical parameters. We also offer rules for the optimal fraction of fossil fuel reserves that should be left in the crust of the earth (cf. Carbon Tracker 2013; McGlade and Ekins 2015) and the optimal transition time to the carbon-free era. Our calculations require only a pencil and the back of an envelope, but yield values very close to those obtained from numerically maximising welfare with a detailed IAM of growth, development, energy, and climate change. We hope that our simple arithmetic helps policy makers and climate scientists to gain a better understanding of the ethical, economic, and geophysical drivers of optimal climate policy. ${ }^{1}$

The outlay of the paper is as follows. The "The carbon cycle and the cost of emitting carbon" section discusses the multi-box carbon cycle and the cost of emitting carbon, the "Intergenerational ethics and the risk-adjusted discount rate" section discusses the intergenerational ethics and the riskadjusted discount rate, the "Simple rule for the global price of carbon" section presents our simple rule for the optimal price of carbon, the "The energy transition, the carbon budget, and stranded fossil fuel reserves" section derives the optimal carbon budget and the amount of stranded fossil fuel reserves, and the "End of carbon era and peak

\footnotetext{
${ }^{1}$ Allen (2016) also offers a simple framework for analysing the drivers of peak warming and the optimal carbon budget in a consumermaximising world, but focuses on the need for carbon capture and sequestration rather than the transition to renewable energy and does not discuss the ethical drivers of climate policy or the optimal timing of the transition to the carbon-free era.
}

warming" section shows how to calculate the onset of the carbon-free era and peak warming and derives the effects of energy efficiency. The "Putting it together" section puts it all together, and the "Calibration and illustrative policy simulations" section offers a calibration and illustrates our analysis with some simulations. The "Implementing the $2{ }^{\circ} \mathrm{C}$ target" section shows how to take account of a $2{ }^{\circ} \mathrm{C}$ upper limit on global warming. The "Performance of the simple rules" section shows how well our simple arithmetic of climate policy performs in a full integrated assessment model. The "Carbon capture and sequestration as backstop" section discusses carbon capture and sequestration. The "Conclusion" section concludes.

\section{The carbon cycle and the cost of emitting carbon}

The global price of emitting carbon, $P$, should generally be set to the social cost of carbon, which is the present discounted value of all future economic damages from emitting one ton of carbon today. This price can be levied via either a carbon tax or an emissions permit. To compute future economic damages, we allow for $n$ different parts of the atmospheric carbon stock each one of them decaying at a different rate. This leads to a so-called $n$-box model of the carbon cycle. With the fraction $a_{i}$ of each emitted ton entering a box $i$ with exponential decay rate $b_{i}$, the amount left in the atmosphere after $t$ years equals $\sum_{i=1}^{n} a_{i}\left(1-b_{i}\right)^{t}$. The easiest is to have a twobox carbon cycle (i.e. $n=2$ ) with the first box consisting of the permanent component of atmospheric carbon which corresponds to the $20 \%$ of carbon emissions stays up for thousands of years in the atmosphere $\left(a_{1}=0.2, b_{1}=0\right)$ and a second box consisting of the transient component of atmospheric carbon $\left(a_{2}=0.32\right.$ and $\left.b_{2}=0.0023\right)$. Such a simple modelling of the carbon cycle captures well the carbon cycle of the most prominent IAM, i.e. DICE set out in Nordhaus (2008) (Golosov et al. 2014). ${ }^{2}$

Next, we assume that the flow damage at time $t$ of an extra ton of atmospheric carbon is proportional to world GDP, i.e. $d \mathrm{GDP}_{t}$, where $d$ is estimated to be $5.3 \%$ of

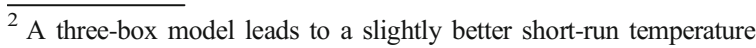
response (Gerlagh and Liski 2017).
} 
GDP at roughly $2{ }^{\circ} \mathrm{C}$ based on DICE and does not vary much with temperature (Golosov et al. 2014). ${ }^{3}$ It takes a long time before changes in the stock of atmospheric carbon affect global mean temperature and cause damages to aggregate production. We model this by allowing for a simple exponential lag between projected global mean temperature and the damages that result from that on the one hand and the stock of atmospheric carbon of $l$ years on the other hand. We denote the mean of this exponential lag by the parameter $l$. In our baseline calibration, we take this mean lag $l$ to be 70 years.

\section{Intergenerational ethics and the risk-adjusted discount rate}

Given that climate change resulting from burning carbon today occurs decades or centuries ahead, the flow damages computed above have to be summed and discounted taking account of the slow uptake of atmospheric carbon in biosphere and oceans. Economists use the social discount rate, $S D R$, for this, which is a concept that has been hotly debated in climate economics (Stern 2007; Nordhaus 2007; Weitzman 2007). The pure rate of time preference or alternatively the rate of time impatience is denoted by $R T I$. The growth-corrected social discount rate, i.e. SDR $g$, consists of the RTI plus four corrections to allow for the rising affluence of generations, damages growing at the same rate as world GDP, risk aversion and prudence, and stochastic shocks to damages being proportional to shocks to future world GDP, respectively. These corrections are summarised by the following generalised Keynes-Ramsey rule for distributing consumption optimally over time:

$\mathrm{SDR}-g=\mathrm{RTI}+\mathrm{IIA} \times g-g-\frac{1}{2} \times \mathrm{RRA} \times \mathrm{PRU} \times \sigma^{2}+\mathrm{RRA} \times \sigma^{2}$

(e.g. Gollier 2013). The first two terms on the right-hand side of the expression (1) trade off the rate of time impatience, RTI, which indicates how much less valuable consumption of future generations is simply because it occurs in the future, and the ethical judgement about the permissible levels of income inequality across generations. If living standards are proxied by the world GDP and grow at a constant rate $g>0$, future generations will be richer

\footnotetext{
${ }_{3}^{3}$ Most IAMs assume damages as a fraction of GDP to be convex in temperature while temperature is usually concave (logarithmic) in atmospheric concentrations so that the overall effect gives a near linear relationship.
}

than current generations and the latter should be spared costly investments simply because they are poorer already. This effect is strong if the growth rate, $g$, and the coefficient of relative intergenerational inequality aversion, denoted by IIA, are large. Note that the parameter IIA in this second term corresponds to the inverse of the usual elasticity of marginal consumption (often denoted by $\eta$ ) and for the case of expected utility analysis corresponds to the inverse of the coefficient of relative risk aversion, denoted by $R R A$, too. With more general non-expected utility analysis, the two parameters IIA and RRA can be freely chosen from each other and the parameter restriction IIA $=1 /$ RRA no longer needs to hold (Epstein and Zin 1989). The third term in (1) is $-g$ and ensures that the SDR is the growthcorrected social discount rate to reflect that damages from global warming are proportional to world GDP and thus grow at the rate $g$ too. The fourth term in (1) is the SDR and corresponds to the prudence effect, which is large if the variance of expected future consumption growth, denoted by $\sigma^{2}$, the coefficient of relative risk aversion, RRA, and the coefficient of relative prudence, denoted by $P R U$ (which is equal to 1+IIA for power utility functions and for Epstein-Zin preferences), are high (cf. Kimball 1990). It pushes down the SDR and will make climate policy more ambitious. The fifth term in (1) captures risk aversion with respect to uncertainty about future damages which are perfectly correlated with future GDP. It pushes up the SDR and will make climate policy less ambitious, since shocks that increase future damages also increase future GDP and are thus easier to take care of in the future. This is akin to a "climate beta" effect (cf. Dietz et al. 2017).

We can rewrite (1) to obtain an alternative expression for the growth-corrected SDR:

$\mathrm{SDR}-g=\mathrm{RTI}+(\mathrm{IIA}-1) \times \tilde{g}$ with $\quad \tilde{g} \equiv g-\frac{1}{2} \times \mathrm{RRA} \times \sigma^{2}$,

where $\tilde{g}$ is the trend growth rate corrected for risk aversion with respect to uncertain future consumption growth and consequent damages from global warming. ${ }^{4}$ Following Nordhaus (2008), we use baseline values for the RTI of $1.5 \%$ per annum and for the IIA and the RRA of 1.45. The baseline standard deviation of global annual consumption growth had a standard deviation of $3.6 \%$ over much of the past century and our baseline thus sets $\sigma=0.036$. Hence, the growth correction to allow for both prudence and stochastic damages in expression

\footnotetext{
$\overline{{ }^{4} \text { Gollier (2013) }}$ uses SDR $=$ RTI + IIA $\times g-0.5$ RRA $\times$ PRU $\times \sigma^{2}$,
} where PRU $=1+$ IIA. 
$\left(1^{\prime}\right)$, i.e. $-0.5 \times \mathrm{RRA} \times \sigma^{2}$, is only $-0.094 \%$ per annum which depresses the growth-corrected SDR by a mere $0.042 \%$ per annum, i.e. $-0.5 \times($ IIA -1$) \times$ RRA $\times \sigma^{2}$. The prudence term in expression (1), i.e. $-0.5 \times \mathrm{RRA} \times$ PRU $\times \sigma^{2}$, depresses the SDR by $0.23 \%$ per annum.

\section{Simple rule for the global price of carbon}

Taking the present value of the flow damages of what is left in the atmosphere at each future point of time and using (1') for the growth-corrected SDR gives our rule for the optimal price of carbon, $P$ :

$P=\Omega d \mathrm{GDP}$ with $\Omega \cong\left(\frac{1}{1+(\mathrm{SDR}-g) l}\right) \sum_{i=1}^{n}\left(\frac{a_{i}\left(1-b_{i}\right)}{\mathrm{SDR}-g+b_{i}}\right)$.

This rule offers the following insights into the drivers of climate policy. First, the optimal global price of carbon is proportional to and rises with world GDP, about 66 trillion US dollars in 2010, and to the flow cost of global warming per ton of emitted carbon, $d$. Second, the global carbon price is high if the SDR is low, which from (1) is the case if welfare of future generations is not discounted much (low RTI) and, given trend GDP growth, intergenerational inequality aversion is weak (low IIA). Third, if IIA $>1$, the ethical positive effect of higher trend growth (higher $g$ ) on the SDR via richer future generations dominates the negative effect on SDR $-g$ due to faster growing damages of global warming. This depresses the optimal price of carbon. In contrast, more uncertainty about future consumption growth, especially if risk aversion is substantial (high RRA), curbs the growth-corrected discount rate and boosts the price of carbon. Fourth, lower decay rates of atmospheric carbon (higher $b_{i}$ ) and a shorter temperature lag (low $l$ ) increase the carbon price due to longerlasting and more immediate damages. Energy efficiency does not impact the optimal price of carbon.

\section{The energy transition, the carbon budget, and stranded fossil fuel reserves}

Recent studies quantify the amount of fossil fuel which must be abandoned in the crust of the earth for global warming to stay below $2{ }^{\circ} \mathrm{C}$ (McGlade and Ekins 2015). ${ }^{5}$ Underlying such estimates is the basic economic idea that fossil fuels are used as long as they are cheaper than renewable energy. The carbon price increases the cost of fossil energy and ensures that renewable energy is phased in earlier. To estimate the optimal carbon budget, we suppose that the cost of extracting one ton of carbon falls with time due to directed technical progress at the rate $r_{E}$ (e.g. due to the recent innovation of horizontal drilling in fracking shale gas) and becomes more expensive over time as less accessible fields have to be explored, hence $E(t)=E_{0}\left(1-r_{E}\right){ }^{t}\left(S_{0} / S(t)\right)^{e_{1}}$ with $S(t)$ denoting reserves at time $t$. We calibrate the initial cost of fossil fuel extraction so that the energy sector is $5 \%$ of GDP, hence $E_{0}=0.35 \mathrm{~T} \$ / \mathrm{GtC}$, and set $S_{0}=10,000 \mathrm{GtC}$, $e_{1}=0.5$, and $r_{E}=0$ (cf. Rezai and van der Ploeg 2016). The cost of renewable energy $R$ (including cost of infrastructure and feed-in subsidies to foster learning by doing) falls at the rate $r_{R}$ due to directed technical progress, where following Nordhaus (2014), we suppose that producing from carbon-free alternatives costs $5.6 \%$ of GDP today and $2.7 \%$ of GDP at the end of the century, hence $R_{0}=0.8 \mathrm{~T} \$ / \mathrm{GtCe}$ and $r_{R}=1 \%$ per annum until the price of renewable energy reaches its lower floor of $0.4 \mathrm{~T} \$ /$ GtCe near the end of the century (cf. Rezai and van der Ploeg 2016). At time $T, E(T)+P(T)=R_{0}\left(1-r_{R}\right)^{T}$ so from then onwards, fossil fuel is too expensive and is priced out of the market. This transition condition gives the optimal cumulative emissions or the carbon budget for short, $B \equiv S_{0}-S(T)$ :

$B=S_{0}\left[1-\left(\frac{E_{0}\left(1-r_{E}\right)^{T}}{R_{0}\left(1-r_{R}\right)^{T}-\Omega(\mathrm{SDR}, g) d(1+g)^{T} \mathrm{GDP}_{0}}\right)^{\frac{1}{e_{1}}}\right]$.

The carbon budget is low if fossil fuel is expensive to extract and if renewable energy is cheap to produce (high $E_{0}$ and low $R_{0}$ ). The carbon budget is curbed by the ethical, economic, and geophysical factors that drive up the price of carbon (high SDR - $g$ or high $\Omega$ from (1) and (2), high $d$ and high $\mathrm{GDP}_{0}$ ). If fossil fuel extraction is expected to experience rapid directed technical progress, the optimal carbon budget will be higher. If renewable energy is expected to experience rapid technical progress (as is the case now for solar energy), the optimal carbon budget ends up lower as climate policy

\footnotetext{
5 This study follows Meinshausen et al. (2009) by focusing on cumulative emissions up to 2050. This is misleading as peak global warming depends on cumulative emissions forever into the future (e.g. Allen et al. 2009; Allen 2016).
} 
has become cheaper. The fraction of stranded fossil fuel assets, $S(T) / S_{0}=\left(S_{0}-B\right) / S_{0}$, is then high.

\section{End of carbon era and peak warming}

Generally, more energy-efficient technologies are described in a stylised fashion as using higher capital and less energy inputs. Such technologies arise when less fossil fuel energy inputs are used in favour of more capital in response to, say, a tax on the use of fossil fuel. However, empirical evidence suggests that there is limited substitutability between energy and capital and labour (Hassler et al. 2012) in which case fossil fuel use is proportional to aggregate output. More specifically, fossil fuel use is given by $\gamma_{0}\left(1-r_{\gamma}\right)^{t} \mathrm{GDP}_{t}$ where the initial energy intensity $\gamma_{0}$ is calibrated at $0.15 \mathrm{GtC}$ per trillion dollars of world GDP (cf. Rezai and van der Ploeg 2016). There might be a negative exponential trend in the energy intensity or carbon intensities of output at the rate $r_{\gamma} \geq 0$. If $r_{\gamma}>0$, then the energy efficiency of the world economy increases over time. A different way of looking at this is that renewable energies and fossil fuel energies are bad substitutes as long as the problem of storage is not solved in a cost-efficient manner. More efficient-energy technologies can then be seen as those which use more renewable and less fossil fuel energies.

The carbon era ends when the total carbon emitted equals the carbon budget, $B$. This implies that $B=\sum_{t=1}^{T}(1+g)^{t} \gamma_{0}\left(1-r_{\gamma}\right)^{t} \mathrm{GDP}_{0} \cong\left[\left(1+g-r_{\gamma}\right)^{T+1}-1\right.$ ]$\gamma \mathrm{GDP}_{0} /\left(g-r_{\gamma}\right)$, and thus gives the optimal transition time to the carbon-free era:

$T=\frac{1}{g-r_{\gamma}} \ln \left(1+\left(g-r_{\gamma}\right) \frac{B}{\gamma_{0} \mathrm{GDP}_{0}}\right)-1 \quad$ if $\quad r_{\gamma} \neq g, \quad T=\frac{B}{\gamma_{0} \mathrm{GDP}_{0}}-1 \quad r_{\gamma}=g$.

The transition thus occurs more quickly if the carbon budget $B$ is small, expected economic growth $g$ is high, and the rate of increase in energy efficiency $r_{\gamma}$ is small. To analyse the effect of increases in energy efficiency, we first note from (1) that this does not affect the optimal price of carbon. We note from (4) that both a higher carbon budget $B$ and a higher energy efficiency leads to a longer fossil fuel phase T. Equation (3) indicates that cumulative emissions decrease with the length of the fossil fuel phase $T$. The reason is that, if the time of the switch to the carbon-free era takes place later, technical progress in the renewable energies industry has led to a lower cost of renewables and economic growth has led to a higher cost of carbon. Assuming that these outweigh the effect of technical progress on costs in the fossil fuel industry, we see that higher $T$ must be associated with lower fossil fuel extraction cost and thus a lower cumulative extraction $B$. Combining the comparative statics of Eqs. (3) and (4), we thus deduce that higher energy efficiency or a rising trend in energy efficiency leads to lower cumulative emissions and a longer fossil fuel phase (lower $B$, higher $T$ ).
Finally, there is a robust relationship between cumulative emissions and peak warming as the pathway of carbon emissions matters less than the cumulative emissions $B$ (Allen et al. 2009):

$\mathrm{PW}=\Phi(B), \quad \Phi^{\prime}>0, \quad \Phi^{\prime \prime} \leq 0$.

Although a linear approximation to (5) works reasonably well (Allen 2016), we use a quadratic which is slightly more accurate. ${ }^{6}$ The carbon budget from preindustrial times onwards corresponding to a maximum of $2{ }^{\circ} \mathrm{C}$ is $1 \mathrm{TtC}$, implying a carbon budget for cumulative emissions of $350 \mathrm{GtC}$ or $1283 \mathrm{GtCO}_{2}$ from 2010 onwards.

\section{Putting it together}

Figure 1 solves (3) through (5) for the carbon budget $B$, the time $T$ that the carbon-free era starts, and peak warming, both for the social optimum if carbon is priced (see the

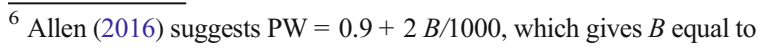
$550 \mathrm{GtC}$ or $2017 \mathrm{GtCO}_{2}$. See Appendix A.
} 
upward-sloping solid line) according to (1) and (2) and for the business-as-usual scenario (BAU, see the upwardsloping dashed line) if climate policy is absent $(P=0){ }^{7}$ In the bottom panel of Fig. 1, the carbon budget $B$ falls through (3) as the price of carbon is imposed. This implies a quicker transition to renewable energy and lower peak warming (left axis). The top panel illustrates the underlying transitional dynamics in the energy market. As cumulative emissions increase, the cost of extracting the remaining stock fossil fuel increases. Simultaneously, the cost of renewable energy decreases. The top panel shows that the transition to the carbon-free era occurs when the cost of fossil fuel has just exceeded that of renewable energy. The difference between the climate policy (the upwardsloping solid line in the top panel of Fig. 1) and BAU (the upward-sloping dashed line) scenarios is the rising carbon tax as determined by rule (2).

From (2), we know that a smaller SDR (due to more patience, less intergenerational inequality aversion and, if IIA > 1, lower trend GDP growth and more risk aversion), a lower decay rate, and a shorter temperature lag push up the carbon price and shift up the upwardsloping solid climate policy line in the top panel of Fig. 1. Renewable energy then becomes competitive earlier when energy cost is relatively higher, leaving a bigger fraction of fossil fuel reserves stranded, and cutting cumulative emissions and peak warming.

If the coefficient of intergenerational inequality aversion exceeds unity (IIA $>1$ ), faster trend GDP growth makes future generations richer and decreases the ethical onus on current generations to curb emissions, especially if IIA is high, so the SDR rises and climate policy becomes less ambitious and temperature rises. A lower and falling cost of renewable energy shifts down the cost curve in the top panel (the downward-sloping solid line), which curbs the carbon budget, brings forward the carbon-free era and cuts peak warming. The energy cost at the time of transition is now relatively lower.

\section{Calibration and illustrative policy simulations}

Figure 1 and also the results of our back-of-the-envelope calculation shown in Table 2 that follow this are based on

\footnotetext{
${ }^{7}$ We need to solve the simultaneous equations (3) and (4) for $B$ and $T$, which is done in the Excel sheet accompanying this paper. Only with no technical change whatsoever, $g=r_{E}=r_{R}=0$, is the system recursive.
}

the baseline calibration summarised in Table 1 . We find that in the baseline case with carbon pricing $1046 \mathrm{GtC}$ is burnt and global mean temperature relative to preindustrial temperatures peaks at $2.8{ }^{\circ} \mathrm{C}$. With a growthcorrected social discount rate of $2.36 \%$ per year, the initial optimal carbon price is $\$ 27.5 / \mathrm{tC}$ and grows at $2 \%$ per year from then on. The fossil fuel phase lasts 56 years.

Table 2 also reports some sensitivity exercises by illustrating the impact of ethical and economic drivers on the optimal carbon budget and peak warming. Ethical considerations influence the transition to renewable energy through the optimal carbon price. As society's aversion to intergenerational inequality falls from 1.45 to 0.5 , peak warming falls from 2.8 to $1.8^{\circ} \mathrm{C}$ and the carbon budget from 1046 to $264 \mathrm{GtC}$. Similarly, not discounting welfare of future generations at all, i.e. $\mathrm{RTI}=0$, cuts peak warming to $2.1^{\circ} \mathrm{C}$ and the carbon budget to $465 \mathrm{GtC}$.

If global economic growth slows from 2 to $1 \%$ per annum, future material affluence will be lower and the initial carbon price rises in order to shield future generations from climate-related damages to their weakened economy. Peak warming declines to $2.6{ }^{\circ} \mathrm{C}$ corresponding to a fall of the carbon budget to $836 \mathrm{GtC}$. Higher vulnerability of the economy to climate change in the form of higher damages has a similar effect on peak warming and the carbon budget. A 20\% reduction in today's cost of renewable (fossil) energy significantly expedites (delays) the transition to the carbon-free era and decreases (increases) peak warming to $2.3{ }^{\circ} \mathrm{C}$ $\left(3.2{ }^{\circ} \mathrm{C}\right)$ and the carbon budget to $642 \mathrm{GtC}(1419$ $\mathrm{GtC}$ ). An acceleration of directed technical change in the renewable sector from 1 to $2 \%$ per annum brings forward the energy transition and cuts peak warming to $2.1{ }^{\circ} \mathrm{C}$ and the carbon budget to $473 \mathrm{GtC}$. The model can be used to calculate the impacts of shifts in the geophysical components in a similar fashion.

To illustrate the trade-offs between ethical and economic drivers, Fig. 2 shows contours of given peak warming levels for different economic and ethical parameters. The left panel of Fig. 2 shows how the discount rate and the initial cost of renewable energy affect the optimal degree of peak global warming. Lower peak warming requires shifting closer to the origin, i.e. lower levels of discounting and initial costs. It also illustrates how, given an ethical parameter, peak warming can be brought down by subsidies to renewable energy. The right panel of Fig. 2 shows how optimal degrees of peak global warming can be achieved by different levels of IIA and the rate of directed technical change. 
Fig. 1 The rules (1)-(2) give the carbon budget and end of carbon era from (3)-(4) and peak warming from (5) in the bottom panel. The top panel illustrates the dynamics as fossil fuel extraction costs and the carbon price rise and the cost of renewable energy falls

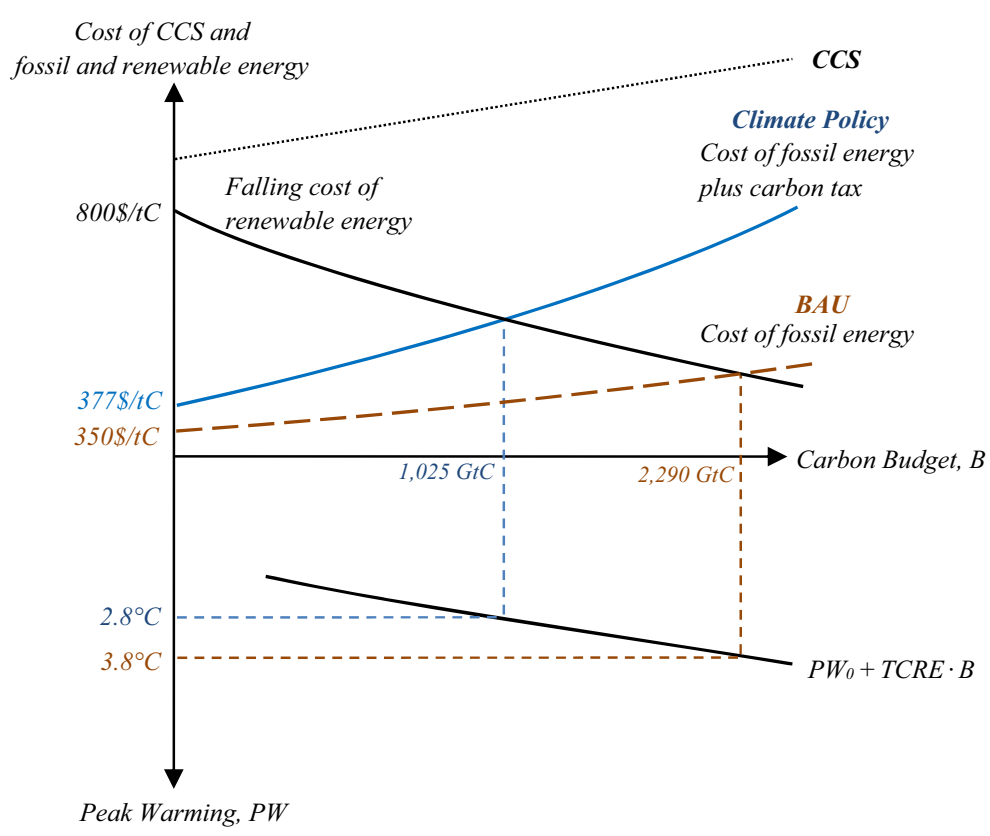

Peak warming can be lowered by moving to the upper-left corner: lower preparedness to sacrifice utility to cut future global warming (higher IIA) requires more technical progress (higher $r_{R}$ ) through policies stimulating innovation and R\&D. Both panels illustrate how big the challenge and how ambitious policies must be to stay well below $2{ }^{\circ} \mathrm{C}$ peak warming as agreed in Paris.

Table 1 Baseline calibration of the back-on-the-envelope IAM

\section{Ethical}

Rate of time impatience: $\mathrm{RTI}=1.5 \%$ year

Relative intergenerational inequality aversion and risk aversion: $\mathrm{IIA}=\mathrm{RRA}=1.45$

Economic

World economy: GDP0 $=66 \mathrm{~T} \$$, rate of growth: $g=2 \% /$ year, volatility: $\sigma=0.036$,

Fossil fuel use per unit of world GDP: $\gamma_{0}=0.15 \mathrm{GtC} / \mathrm{T} \$$, rate of decline: $r_{\gamma}=0 \% /$ year

Fossil fuel cost: $E_{0}=0.35 \mathrm{~T} \$ / \mathrm{GtC}, r_{E}=0, e_{1}=0.5$,

Renewable energy cost: $R_{0}=0.8 \mathrm{~T} \$ / \mathrm{GtC}$, rate of decline: $r_{R}=1 \% /$ year

Flow damage as fraction of world GDP: $d=0.053 \$ / \mathrm{tC}$

Geophysical

Initial stock of fossil fuel reserves: $S_{0}=10,000 \mathrm{GtC}$

Coefficients permanent and transient box of carbon cycle: $a_{1}=0.2, b_{1}=0, a_{2}=0.32, b_{2}=0.0023$

Average lag between temperature/damages and carbon stock: $l=70$ years

Transient climate response to cumulative emissions: $\mathrm{TCRE}=2{ }^{\circ} \mathrm{C} / \mathrm{TtC}$
Finally, let us now perform a sensitivity exercise where the rate of increase in energy efficiency is 1.5 or $1 \%$ instead of zero per year (i.e. $r_{\gamma}=0.015$ /year or 0.01 / year). The price of carbon is unaffected. From Eqs. (3) and (4), we can calculate that the safe carbon budget drops from $1046 \mathrm{GtC}$ in the benchmark to 674 or 856 $\mathrm{GtC}$ and that the transition to the carbon-free era then takes only a little longer, 58 or 57 years, respectively, instead of 56 years.

Table 2 Sensitivity of peak warming and carbon budget to ethical and economic drivers

\begin{tabular}{|c|c|c|}
\hline Scenario & $\begin{array}{l}\mathrm{PW} \\
\left({ }^{\circ} \mathrm{C}\right)\end{array}$ & $\begin{array}{l}\text { Carbon } \\
\text { budget (GtC) }\end{array}$ \\
\hline Baseline & 2.8 & 1046 \\
\hline \multicolumn{3}{|l|}{ Ethical } \\
\hline Lower inequality aversion $($ IIA $=0.5$ ) & 1.8 & 264 \\
\hline Lower discount rate $(\mathrm{RTI}=0 \% /$ year $)$ & 2.1 & 465 \\
\hline \multicolumn{3}{|l|}{ Economic } \\
\hline $\begin{array}{l}\text { Lower economic growth rate } \\
\qquad(g=1 \% / \text { year })\end{array}$ & 2.6 & 836 \\
\hline High Damage scenario $(d=0.08)$ & 2.6 & 885 \\
\hline $\begin{array}{l}\text { Lower initial cost of renewable energy } \\
\qquad\left(R_{0}=0.64 \$ \mathrm{~T} / \mathrm{GtC}\right)\end{array}$ & 2.3 & 642 \\
\hline $\begin{array}{l}\text { Lower initial cost of fossil energy } \\
\qquad\left(E_{0}=0.28 \$ \mathrm{~T} / \mathrm{GtC}\right)\end{array}$ & 3.2 & 1419 \\
\hline $\begin{array}{l}\text { Faster reductions in cost of renewable } \\
\text { energy }\left(r_{\mathrm{r}}=2 \% / \text { year }\right)\end{array}$ & 2.1 & 474 \\
\hline
\end{tabular}




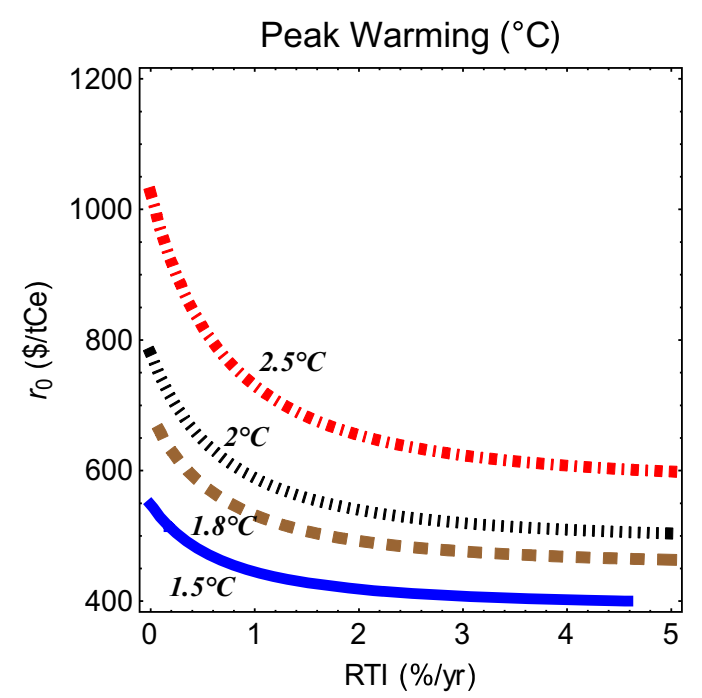

Fig. 2 Economic vs. ethical drivers of peak global warming

\section{Implementing the $2^{\circ} \mathrm{C}$ target}

At the 2015 Paris Summit, it has been agreed to limit global warming well below $2{ }^{\circ} \mathrm{C}$ and to drive efforts to limit the temperature increase to even further $1.5^{\circ} \mathrm{C}$. This is lower than justified by the damages of global warming estimated by economists and used by us. An extra safety margin may be justified to curb risks of tipping points and run-away global warming. A $2{ }^{\circ} \mathrm{C}$ upper bound tells us from (5) or the bottom panel of Fig. 1 that the associated carbon budget should be on average $411 \mathrm{GtC}$ instead of $1000 \mathrm{GtC}$. Under the assumption that the damages used in our calibration are an under-estimate, we raise damages just high enough to ensure that the carbon budget is compatible with the $2{ }^{\circ} \mathrm{C}$ cap on global warming. These

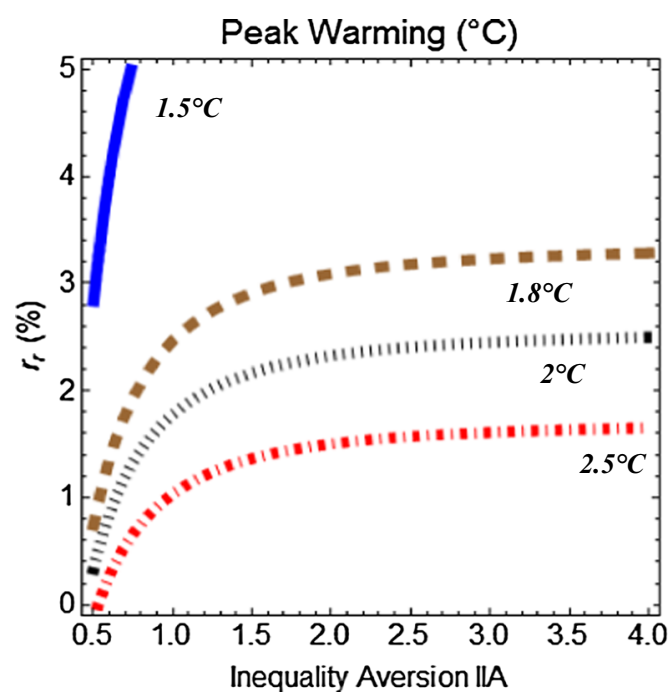

higher damages require from (3) a higher carbon price: at the transition to the carbon-free era, it should be $230 \$ / \mathrm{tC}$ for most scenarios. We back out from (4) that the transition to the carbon-free era is further brought forward from 56 to 30 years. These results are confirmed by simulations for the optimal baseline and the $2{ }^{\circ} \mathrm{C}$ upper bound scenarios in our full-scale IAM as shown in Fig. 3.

An alternative to adjusting damages from global warming upwards to ensure that peak warming does not exceed $2{ }^{\circ} \mathrm{C}$ is to abstract from damages entirely and simply minimise the present discounted value of costs subject to the constraint that peak warming must not exceed $2{ }^{\circ} \mathrm{C}$. This is what is done in the integrated assessment literature and the resulting price of carbon follows a Hotelling path and thus rises more rapidly at a

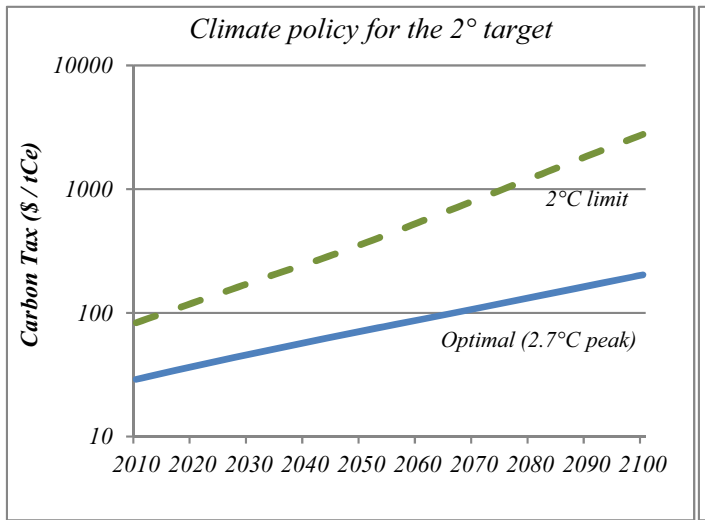

Fig. 3 The $2{ }^{\circ} \mathrm{C}$ upper bound pushes up the required carbon price and requires steeper growth as the unconstrained price yields too high temperature rises $(l e f t)$. Fossil fuel emissions grow at the rate

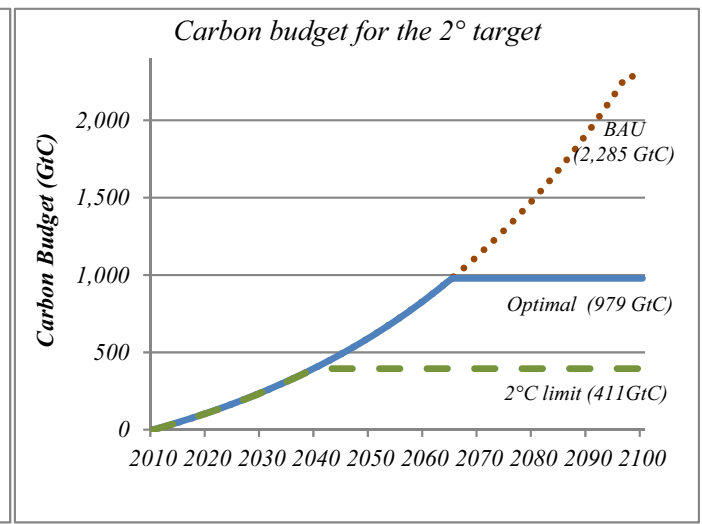

of economic growth until renewable energy is cheaper. The carbon tax brings forward the carbon-free era and leaves a bigger fraction of stranded assets (right) 
rate equal to the rate of interest instead of the rate of economic growth (e.g. Nordhaus 1982; Tol 2013; Bauer et al. 2015). The more rapidly rising price of carbon then reflects the increasing scarcity of carbon as the carbon budget approaches exhaustion. However, if allowance is made for the inertia between changes in global mean temperature and the stock of atmospheric carbon, the optimal price of carbon may follow an inverse U-shaped path and grows more slowly than the Hotelling path (Lemoine and Rudik 2017). Combining the two approach by maximising welfare net of global warming subject to the cap on peak warming or equivalently subject to cumulative emissions being less than the safe carbon budget gives a higher price of carbon than the unconstrained welfare maximisation which grows at a rate somewhere in between the interest rate and the rate of economic growth (van der Ploeg 2017).

\section{Performance of the simple rules}

Most integrated assessment modellers make many additional, and perhaps more realistic, assumptions about economic damages of climate change or dynamics of specific energy sources and crunch out the optimal price of carbon (and sometimes also the stock of stranded fossil fuel assets) by numerically maximising welfare subject to the constraints of their large-scale IAM. The question is how well our simple rules (1) through (5) perform and compare with the optimal time path of carbon prices, carbon budgets, and transition times derived from more complex optimising IAMs. Table 3 therefore compares them with the globally optimal discretionary outcomes and the BAU outcomes for our IAM with DICE damages and Oxford carbon and temperature dynamics. $^{8}$

Our toy IAM performs remarkably well, despite being based on a simple two-box carbon cycle, and adapts accurately to changes in ethical judgement and technological progress (cf. Rezai and van der Ploeg 2016). Cumulative fossil use differs by at most $8 \%$, peak temperature by $0.08{ }^{\circ} \mathrm{C}$, and the initial optimal carbon price by $14 \$ / \mathrm{tC}{ }^{9}$ The transition times are also predicted well

\footnotetext{
${ }^{8}$ With uncertainty about future consumption growth, the SDR in the baseline is cut by $0.14 \%$ per annum. This curbs the carbon budget and peak global warming by only $36 \mathrm{GtC}$ and $0.04{ }^{\circ} \mathrm{C}$, respectively.

${ }_{9}$ Allen (2016) proposes an initial carbon tax of $91 \$ / \mathrm{tC}\left(25 \$ / \mathrm{tCO}_{2}\right)$ in a framework with SDR $-g=1.5 \% /$ year and where marginal damages and the carbon tax (2) are linear in GDP.
}

by the simple rules (e.g. for the baseline 55 and 56 years for the IAM and for the simple rule, respectively. The social optimum avoids the peak temperatures of around $3.9{ }^{\circ} \mathrm{C}$ by locking up much more fossil fuel than the average $2250 \mathrm{GtC}$ burnt under BAU and by transitioning to the carbon-free era in 56 years instead of the end of the century.

\section{Carbon capture and sequestration as backstop}

Allen et al. 2009 have argued that there should be a mandate that ensures all carbon emissions above the budget compatible with $2{ }^{\circ} \mathrm{C}$ global warming should be captured and sequestrated. Allen (2016) further argued that considerations for the near-term mitigation efforts induced by pricing carbon should be disregarded for long-term impacts of the carbon price for sequestration efforts once the optimal carbon budget will have been reached. Although this plea resonates, a simple cap is not necessarily an efficient strategy. It is more efficient to price carbon as this offers a direct incentive to capture and sequester carbon (as well as to make renewable energy more attractive to use and develop and to phase out fossil fuel more quickly). Furthermore, a price for carbon allows trading to promote the least costly cuts in carbon emissions. It avoids the government "picking winners" and instead promotes development of a wide variety of renewable energy sources including carbon capture and sequestration (CCS). This is important as CCS will, like many other potential new sources of renewable energy, be at most a partial solution to the climate challenge. But CCS faces particular challenges: huge capital investments, environmental hazards, and ugly NIMBY politics. Also, as CCS requires lots of space, it is difficult to scale up as costs rise as space is used up. Abatement with CCS (e.g. new coal, coal retrofit, industrial) is still one of the more expensive forms of abatement. Analytically, the cost of fossil fuel with CCS equals $E(t)=E_{0}$ $\left(1-r_{E}\right){ }^{t}\left(S_{0} / S(t)\right)^{e_{1}}$ per ton of carbon plus the marginal cost of abating one ton of carbon, say $A$. This is indicated by the upward-sloping dotted black line in Fig. 1. It follows that, like fossil fuel on its own, the cost of CCS rises as reserves are depleted. It thus only becomes attractive for the market when the marginal cost of abatement falls below the carbon 
Table 3 The simple rules predict the fully fledged IAM outcomes in terms of cumulative emissions and peak temperature well. They also predict the deleterious effects of policy inaction

\begin{tabular}{|c|c|c|c|c|c|c|c|c|c|c|}
\hline \multirow[t]{2}{*}{ Scenario } & \multicolumn{4}{|c|}{ Parameters } & \multicolumn{2}{|c|}{ Optimal carbon budget } & \multicolumn{2}{|c|}{ Peak temperature } & \multicolumn{2}{|c|}{ Initial price } \\
\hline & $\begin{array}{l}\text { RTI } \\
(\%)\end{array}$ & IIA & $\begin{array}{l}g \\
(\%)\end{array}$ & $\begin{array}{l}\text { SDR } \\
(\%)\end{array}$ & $\begin{array}{l}\text { Full IAM } \\
(\mathrm{GtC})\end{array}$ & $\begin{array}{l}\text { Toy IAM } \\
(\mathrm{GtC})\end{array}$ & $\begin{array}{l}\text { Full IAM } \\
\left({ }^{\circ} \mathrm{C}\right)\end{array}$ & $\begin{array}{l}\text { Toy IAM } \\
\left({ }^{\circ} \mathrm{C}\right)\end{array}$ & $\begin{array}{l}\text { Full IAM } \\
(\$ / \mathrm{tC})\end{array}$ & $\begin{array}{l}\text { TOY IAM } \\
(\$ / \mathrm{tC})\end{array}$ \\
\hline $\begin{array}{l}\text { Conventional } \\
(2 \times 2 \times 2)\end{array}$ & 2 & 2 & 2 & 6 & 1,307 & 1293 & 3.06 & 3.07 & 20 & 12 \\
\hline $\begin{array}{l}\text { Baseline } \\
\text { (Nordhaus) }\end{array}$ & 1.5 & 1.45 & 2 & 4.4 & 979 & 1025 & 2.73 & 2.78 & 29 & 27 \\
\hline Lower discounting & 0.1 & 1.45 & 2 & 3 & 569 & 525 & 2.24 & 2.16 & 81 & 95 \\
\hline Lower IIA & 1.5 & 1 & 2 & 3.5 & 759 & 748 & 2.47 & 2.45 & 51 & 55 \\
\hline Lower trend growth & 1.5 & 1.45 & 1 & 3 & 805 & 820 & 2.53 & 2.54 & 37 & 38 \\
\hline Business-as-usual & \multicolumn{10}{|c|}{$\begin{array}{l}\text { Full IAM: cumulative emissions } 2250-2300 \mathrm{GtC} \text {. Peak temperature } 3.89^{\circ} \mathrm{C} \\
\text { Toy IAM: cumulative emissions } 2230-2275 \mathrm{GtC} \text {. Peak temperature } 3.84^{\circ} \mathrm{C}\end{array}$} \\
\hline
\end{tabular}

price. This happens once GDP and the carbon price have risen far enough or when new technology has diminished the cost of CCS sufficiently, but working against this is that once CCS is scaled up, space becomes ever more costly. Given these cost developments, CCS is likely to be dominated by various forms of renewable energy in the market. Forcing it on the market by mandating it is thus an inefficient way to achieve climate objectives and one would hope one does not have to resort to this once it is too late to rely on conventional, more cost-effective climate policies to curb emissions.

\section{Conclusion}

Our assessment of how the optimal carbon price and stranded assets interact with economic growth, renewable energy technology, fossil fuel scarcity, ethical considerations, and fundamental geophysical parameters is transparent and gives easy-tounderstand simple rules that perform well in largescale IAMs. These rules are transparent and robust and in this sense more useful than a discretionary time path of optimal climate policies usually obtained from IAMs. We hope that our back-on-theenvelope framework allows climate scientists not actively engaged in economic modelling to understand the critical assumptions driving the social cost and price of carbon, untapped fossil fuel and the time to reach the carbon-free era in terms of ethical considerations and expected economic growth and cost reductions in renewable energy. In our framework, exogenous improvements in energy efficiency do not affect the optimal price of carbon, but do delay the transition time to the carbon-free era somewhat and provided technical progress in renewable energies or the rate of economic growth are strong enough also depress cumulative emissions and peak global warming significantly.

Our results suggest that the global warming damages estimated and ethical assumptions chosen by economists are likely to lead to global warming that exceeds the $2{ }^{\circ} \mathrm{C}$ target. To ensure that global warming always stays below $2{ }^{\circ} \mathrm{C}$, the carbon price must be raised above what conventional economic damages tell us to do and more fossil fuel must be locked up. In recent estimates of the non-climaterelated health benefits of abandoning fossil fuels (e.g. Parry et al. 2014; Thompson et al. 2014; West et al. 2013; Ščasný et al. 2015), the effects of uncertainty about the steepness of climate damages (Crost and Traeger 2014) and the potential of multiple abrupt disruptions in the climate system (Cai et al. 2016; Lemoine and Traeger 2016) provide ample reasons for raising the carbon price.

Acknowledgements An earlier version of this paper was presented as a keynote at the ECOCOP Workshop, Prague, 3-4 November 2016. We are grateful to the helpful and constructive comments of Milan Ščasný and two anonymous referees. Van der Ploeg is grateful for support from FP7-IDEAS-ERC grant no. 269788. Rezai is grateful for support from the Austrian Science Fund (FWF): J 3633 and OeNB Anniversary Fund (grant no. 15330). 


\section{Appendix}

Cumulative emissions and peak warming

Allen et al. (2009) present a reduced-form model of the climate and argue that cumulative emissions in all future years - rather than the actual emissions profile - matters for peak warming. Figure 4 presents the relationship between peak temperature and this carbon budget in $\mathrm{TtC}$ for over 500 simulations in the optimising variant of our IAM. The quadratic approximation used in our toy IAM is robust and very well determined. The DICE model displays a similar relationship between peak warming and cumulative emissions.

Allen (2016) states that a global temperature increase in line with cumulative $\mathrm{CO}_{2}$ emissions suggests the following simple expression for the temperature response to a pulse emission of an additional ton of $\mathrm{CO}_{2}$ at time $t$ :

$$
\delta \operatorname{Temp}_{t+t^{\prime}}=\operatorname{TCRE} \times\left(1-e^{-\mathrm{KS} \times t^{\prime}}\right),
$$

where $1 / \mathrm{KS}$ is the initial pulse-adjustment time scale of the climate system (of order decade or less) and TCRE is the approximately constant transient climate response to cumulative emissions. This is valid for cumulative emissions up to $5000 \mathrm{GtC}$ and gives the linear approximation

$\mathrm{PW} \cong 0.9^{\circ} \mathrm{C}+T C R E \times B$,

where Allen (2016) uses an initial temperature of and a mid-range value of TCRE $=2^{\circ} \mathrm{C} / \mathrm{TtC}$. Although this linear approximation performs reasonable well for low levels of peak warming (see plot in Fig. 4), we use a

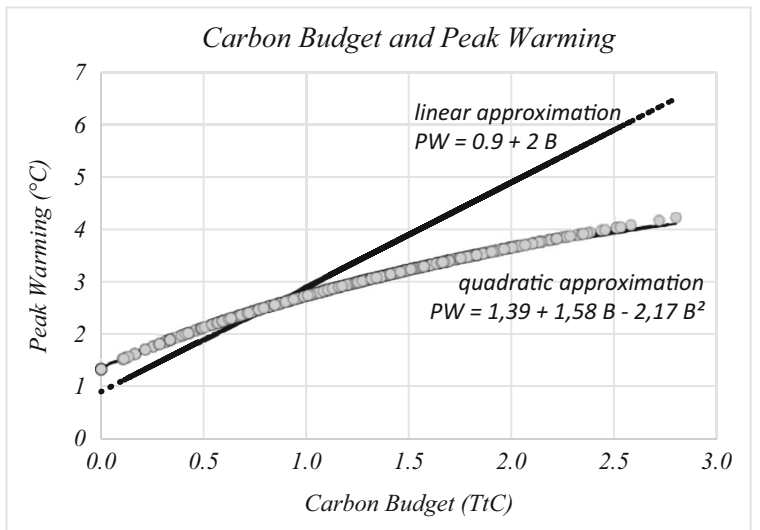

Fig. 4 A robust relationship between the carbon budget and peak warming for the Oxford system based on 500+ simulations in our optimising IAM quadratic approximation which is calibrated to the carbon cycle of the full IAM both in terms of the initial temperature intercept and the slope.

\section{Parameter combinations for $2{ }^{\circ} \mathrm{C}$}

Working backward form a peak warming target of $2{ }^{\circ} \mathrm{C}$, we can use (5) to obtain a carbon budget of $411 \mathrm{GtC}$. We can then use our rules for the carbon tax (1) and (2) and the carbon budget (3) to find out which parameter combinations would make the $2{ }^{\circ} \mathrm{C}$ target feasible. Table 4 collects the pairs of $\left(g\right.$, SDR) consistent with $2{ }^{\circ} \mathrm{C}$ of warming. These can be achieved through combinations of the rate of time impatience (RTI) and the coefficient of relative intergenerational inequality aversion (IIA). Higher levels of growth permit a higher SDR. Since (ignoring the prudence term) $\mathrm{SDR}=\mathrm{RTI}+\mathrm{IIA} \times g$, the permissible values for RTI are higher and the values for IIA lower.

For example, with an economic growth rate of $2 \%$ per annum, the RTI would have to be between 0 and $0.8 \%$ with a corresponding aversion parameter of 1.4-1. If the trend growth rate rises to $3 \%$ per annum, the RTI has to be between 0 and $0.9 \%$ with a corresponding aversion parameter of 1.3-1. The reason for limiting IIA is that as economic growth rises, future generations are deemed rich enough to handle slightly higher temperature increases (in the absence of abrupt climate change). To offset this effect and maintain the $2{ }^{\circ} \mathrm{C}$ target, the permissible parameter range for IIA is lowered as the trend economic growth rate increases.

At the time of the switch to the carbon-free era, 2038, the carbon price has to be $250 \$ / \mathrm{tC}$ in the $2{ }^{\circ} \mathrm{C}$ scenario. The baseline carbon price is then $147.5 \$ / \mathrm{tC}$. Lowering the utility discount rate, keeping IIA at 1.45 , to zero only

Table 4 Parameter combinations that achieve the target of $2{ }^{\circ} \mathrm{C}$ ignoring prudence. Higher trend growth requires less patience and a lower rate of intergenerational inequality aversion

\begin{tabular}{llll}
\hline RTI $(\%)$ & IIA & $g(\%)$ & SDR $(\%)$ \\
\hline 0 & 1.7 & 1 & 1.7 \\
0.25 & 1.45 & 1 & 1.7 \\
0.7 & 1 & 1 & 1.7 \\
0 & 1.4 & 2 & 2.8 \\
0.8 & 1 & 2 & 2.8 \\
0 & 1.3 & 3 & 3.9 \\
0.9 & 1 & 3 & 3.9 \\
\hline
\end{tabular}


raises the carbon price to $108 \$ / \mathrm{tC}$ so that global warming still exceeds $2{ }^{\circ} \mathrm{C}$. If the RTI is cut to zero and the IIA to 1.4 or the RTI is cut to $0.8 \%$ and IIA to 1 , the target of $2{ }^{\circ} \mathrm{C}$ is compatible with DICE damages.

\section{Description of the optimising IAM}

The economic core of our optimising IAM is presented in Rezai and van der Ploeg (2016). However, here we use the Oxford carbon cycle (e.g. Allen et al. 2009) instead of the carbon cycle of DICE or of Golosov et al. (2014). We use our IAM instead of DICE, since we have scarcity rents on fossil fuel and allow extraction costs of fossil fuel to rise as reserves get depleted in order to solve for the optimal amount of stranded assets. The economic part of our IAM is calibrated to data for 2010: world GDP is 66 trillion US \$, the initial capital stock is 150 trillion US \$, and initial energy use is 9.94 GtCe. The world population is 7 billion initially and is assumed to stabilise at 11 billion at the end of the century. We assume a depreciation rate for capital of $10 \%$ per annum and a Cobb-Douglas technology with 30 and $70 \%$ as the shares of capital and labour, respectively. We assume that for each trillion of output that is produced $\gamma=0.150 \mathrm{GtC}$ of fossil fuel is needed, which is in line with a Leontief technology. The initial cost of renewable energy $b(0)$ is initially $\$ 800 / \mathrm{tCe}$. The rate of technical progress in renewable energy is $1 \%$ per annum until the price of renewable energy reaches its lower floor of $\$ 400 / \mathrm{tCe}$ near the end of the century. The cost function for oil extraction has $\$ 350 / \mathrm{tC}\left(e_{0}=0.35\right)$ which gives the share of energy in output of about $5 \%$. Extraction costs evolve with $e_{1}=0.5$ and the initial stock of fossil fuel reserves is $10,000 \mathrm{GtC}$. This means that initially renewable energy is more than twice as expensive as fossil energy initially but renewable energy has the potential to reach current energy prices after all learning has happened.

Our optimising IAM has an initial phase where only fossil fuel is used in the production process, an intermediate phase where fossil fuel and renewable energy are used alongside each other, and a final phase where only renewable energy is used. The economic block of our IAM consists of a capital accumulation equation with an associated Euler equation for the optimal expected growth in consumption per capita and a depletion equation for fossil fuel reserves with an associated modified Hotelling rule describing the scarcity rent as the present value of all future reductions in marginal extraction costs of fossil fuel resulting from burning one ton of carbon today. The Oxford carbon cycle consists relative to the DICE and the two-box carbon cycle of Golosov et al. (2014) of a relatively large number of dynamic equations (i.e. 7) describing the stocks of carbon in the atmosphere and the oceans as well as global temperature. These carbon cycle difference equations have an associated number of difference equations for the costates, which generate the social cost of carbon. Our full optimising IAM thus consists of nine difference equations for the states and another nine for the co-states. Our solution algorithm for this 18-dimensional twopoint boundary value problem solves our IAM in a forward-looking manner such that the transversality conditions are satisfied.

Finally, it should be acknowledged that recently IAMs have been criticised for their lack of proper underpinnings (e.g. Pindyck 2013). In particular, it is difficult to assess the costs and benefits of cutting global warming many decades and centuries ahead, especially when it comes to costs of global warming, the climate sensitivity, and key ethical parameters. In defence, it has been argued that using an IAM is better than no IAM and that there is no reliable alternative to calculate the social cost of carbon (e.g. Metcalf and Stock 2015). Although IAMs are useful in policy debates, we believe their results are difficult to communicate and comprehend. This is the main reason why we advocate the use of transparent and simple framework and an easy-tounderstand rule. This ensures that the communication to policy makers is easier while not suggesting more scientific precision than is warranted (cf. Pindyck 2017).

Open Access This article is distributed under the terms of the Creative Commons Attribution 4.0 International License (http:// creativecommons.org/licenses/by/4.0/), which permits unrestricted use, distribution, and reproduction in any medium, provided you give appropriate credit to the original author(s) and the source, provide a link to the Creative Commons license, and indicate if changes were made.

\section{References}

Allen, M. R. (2016). Drivers of peak warming in a consumptionmaximizing world. Nature Climate Change, 6(7), 684-686. https://doi.org/10.1038/nclimate2977.

Allen, M. R., Frame, D. J., Huntingford, C., Jones, C. D., Lowe, J. A., Meinshausen, M., \& Meinshausen, N. (2009). Warming 
caused by cumulative emissions towards the trillionth tonne. Nature, 458(7242), 1163-1166. https://doi.org/10.1038 /nature08019.

Bauer, N., Bosetti, V., Hamdi-Cheriff, M., Kitous, A., McCollum, D., Mjean, A., Rao, S., Turton, H., Paroussos, L., Ashina, S., Calvin, K., Wada, K., \& van Vuuren, D. (2015). CO2 emission mitigation and fossil fuel markets: dynamic and international aspects of climate policy. Technological Forecasting and Social Change, 90(A), 243-256. https://doi.org/10.1016 j.techfore.2013.09.009.

Cai, Y., Judd, K., Lenton, T. M., \& Lontzek, T. S. (2016). Risk of multiple climate tipping points should trigger a rapid reduction in $\mathrm{CO}_{2}$ emissions. Nature Climate Change, 6(5), 520525. https://doi.org/10.1038/nclimate2964.

Carbon Tracker \& Grantham Research Institute. (2013). Unburnable carbon 2013: wasted capital and stranded assets. London: Grantham Research Institute.

Crost, B., \& Traeger, C. (2014). Optimal $\mathrm{CO}_{2}$ mitigation under damage risk valuation. Nature Climate Change, 4(7), 631636. https://doi.org/10.1038/nclimate2249.

Dietz, S., Gollier, C., \& Kessler, L. (2017). The climate beta. Journal of Environmental Economics and Management. https://doi.org/10.1016/j.jeem.2017.07.005.

Epstein, L. G., \& Zin, S. E. (1989). Substitution, risk aversion, and the temporal behavior of consumption and asset returns: a theoretical framework. Econometrica, 57(4), 937-969. https://doi.org/10.2307/1913778.

Gerlagh, R., \& Liski, M. (2017). Consistent climate policies. Journal of the European Economic Association. https://doi. org/10.1093/jeea/jvx010.

Gollier, C. (2013). Pricing the planet's future. Princeton: Princeton University Press.

Golosov, M., Hassler, J., Krusell, P., \& Tsyvinski, A. (2014). Optimal taxes and fossil fuel in general equilibrium. Econometrica, 82(1), 41-88.

Hassler, J., Krusell, P., \& Olovsson, C. (2012). Energy-saving technical change. NBER Working Paper 18456. Cambridge: Mass.: National Bureau of Economic Research.

Kimball, M. S. (1990). Precautionary saving in the small and in the large. Econometrica, 58(1), 53-73. https://doi.org/10.2307 12938334.

Lemoine, D., \& Rudik, I. (2017). Steering the climate system: using inertia to lower the cost of policy. American Economic Review, 107(10), 2947-2957. https://doi.org/10.1257 /aer.20150986.

Lemoine, D., \& Traeger, C. (2016). Economics of tipping the climate dominoes. Nature Climate Change, 6(5), 514-519. https://doi.org/10.1038/nclimate2902.

McGlade, C., \& Ekins, P. (2015). The geographical distribution of fossil fuels unused when limiting global warming to $2^{\circ} \mathrm{C}$. Nature, 517(7533), 187-190. https://doi.org/10.1038 /nature14016.

Meinshausen, M., Meinshausen, N., Hare, W., Raper, S. C. B., Frieler, K., Knutti, R., Frame, D. J., \& Allen, M. R. (2009). Greenhouse emission targets for limiting global warming to $2^{\circ} \mathrm{C}$. Nature, 458(7242), 1158-1162. https://doi.org/10.1038 /nature08017.

Metcalf, G. E., \& Stock, J. (2015). The role of integrated assessment models in climate policy: a user's guide and assessment,
Discussion Paper 2015-68. Cambridge: Mass.: Harvard Project on Climate Agreements.

Nordhaus, W. (1982). How fast should we graze the global commons? American Economic Review, 72(2), 242-246.

Nordhaus, W. (2007). A review of the Stern Review on the economics of climate change. Journal of Economic Literature, 45(3), 686-702. https://doi.org/10.1257 /jel.45.3.686.

Nordhaus, W. (2008). A question of balance-weighing the options on global warming policies. New Haven: Yale University Press.

Nordhaus, W. (2014). Estimates of the social cost of carbon: concepts and results from the DICE-2013R model and alternative approaches. Journal of the Association of Environmental and Resource Economists, 1(1/2), 273-312. https://doi.org/10.1086/676035.

Parry, I., Veung, C., \& Heine, D. (2014). How much carbon pricing is in countries' own interests? The critical role of co-benefits, CESifo Working Paper 5015. Munich: CESifo.

Pindyck, R. S. (2013). Climate change policy: what do the models tell us? Journal of Economic Literature, 51(3), 860-872. https://doi.org/10.1257/jel.51.3.860.

Pindyck, R. S. (2017). The use and misuse of models for climate policy. Review of Environmental Economics and Policy, 11(1), 100-114. https://doi.org/10.1093/reep/rew012.

Rezai, A., \& van der Ploeg, F. (2016). Intergenerational inequality aversion, growth, and the role of damages: Occam's rule for the global carbon tax. Journal of the Association of Environmental and Resource Economists, 3(2), 493-522. https://doi.org/10.1086/686294.

Ščasný, M., Massetti, E., Melichar, J., \& Carrara, S. (2015). Quantifying the ancillary benefits of the representative concentration pathways on air quality in Europe. Environmental \& Resource Economics, 62(2), 383-415. https://doi. org/10.1007/s10640-015-9969-y.

Stern, N. H. (2007). The economics of climate change: the Stern Review. Cambridge: Cambridge University Press. https://doi. org/10.1017/CBO9780511817434.

Stern, N. (2016). Economics: current climate models are grossly misleading. Nature, 530(7591), 407-409. https://doi. org/10.1038/530407a.

Thompson, T. M., Rausch, S., Saari, R. K., \& Selin, N. E. (2014). A systems approach to evaluating the air quality co-benefits of US carbon policies. Nature Climate Change, 4(10), 917923. https://doi.org/10.1038/nclimate2342.

Tol, R. S. J. (2013). Targets for global climate policy: an overview. Journal of Economic Dynamics and Control, 37(5), 911928. https://doi.org/10.1016/j.jedc.2013.01.001.

van der Ploeg, F. (2017). The safe carbon budget, CESifo Working Paper 6620. Munich: CESifo.

Weitzman, M. L. (2007). A review of the Stern Review on the economics of climate change. Journal of Economic Literature, 45(3), 703-724. https://doi.org/10.1257 /jel.45.3.703.

West, J. J., Smith, S. J., Silva, R. A., Naik, V., Zhang, Y., Adelman, Z., Fry, M. M., Anenberg, S., Horowitz, L. W., \& Lamarque, J.-F. (2013). Co-benefits of global greenhouse gas mitigation for future air quality and human health. Nature Climate Change, 3(10), 885-889. https://doi.org/10.1038 /nclimate2009. 